\title{
Sonodynamic Excitation of Rose Bengal for Eradication of Gram-Positive and Gram-Negative Bacteria
}

\author{
Faina Nakonechny, ${ }^{1,2}$ Michael Nisnevitch, ${ }^{1}$ Yeshayahu Nitzan, ${ }^{2}$ and Marina Nisnevitch ${ }^{1}$ \\ ${ }^{1}$ Department of Chemical Engineering, Biotechnology and Materials, Ariel University Center of Samaria, 40700 Ariel, Israel \\ ${ }^{2}$ The Mina and Everard Goodman Faculty of Life Sciences, Bar-Ilan University, 52900 Ramat-Gan, Israel \\ Correspondence should be addressed to Marina Nisnevitch; marinan@ariel.ac.il
}

Received 24 July 2012; Revised 26 August 2012; Accepted 24 September 2012

Academic Editor: Tim Maisch

Copyright (c) 2013 Faina Nakonechny et al. This is an open access article distributed under the Creative Commons Attribution License, which permits unrestricted use, distribution, and reproduction in any medium, provided the original work is properly cited.

\begin{abstract}
Photodynamic antimicrobial chemotherapy based on photosensitizers activated by illumination is limited by poor penetration of visible light through skin and tissues. In order to overcome this problem, Rose Bengal was excited in the dark by $28 \mathrm{kHz}$ ultrasound and was applied for inactivation of bacteria. It is demonstrated, for the first time, that the sonodynamic technique is effective for eradication of Gram-positive Staphylococcus aureus and Gram-negative Escherichia coli. The net sonodynamic effect was calculated as a 3-4 $\log _{10}$ reduction in bacteria concentration, depending on the cell and the Rose Bengal concentration and the treatment time. Sonodynamic treatment may become a novel and effective form of antimicrobial therapy and can be used for low-temperature sterilization of medical instruments and surgical accessories.
\end{abstract}

\section{Introduction}

The field of photodynamic antimicrobial chemotherapy (PACT) is currently under intense investigation and is showing promising prospects as an alternative to antibiotic treatment in view of increasing widespread bacterial resistance to antibiotics [1,2]. A classical scheme of PACT includes excitation of low toxic components-photosensitizers (PS) by visible light, when light-activated PS molecules transfer energy to molecular oxygen, which results in the production of reactive oxygen species that in turn cause irreversible damage to cellular components [1,3-7]. The list of PS includes a wide spectrum of compounds, such as porphyrins, phenothiaziniums, phthalocyanines, hypocrellin derivatives, squaraine derivatives (squaraine dyes, squaric acid derivatives), boron dipyrromethene derivatives, and chlorine derivatives $[4,6,8]$. PACT has been extensively studied as a strategy against both Gram-positive and Gram-negative bacteria $[9,10]$, including antibiotic-resistant species [11] and appears to occupy a niche for control of oral [12] and other localized infections [11]. It should be noted that no development of bacterial resistance to PS has been reported to date from the numerous studies on the effect of PACT against different microorganisms $[13,14]$.

The major disadvantage of PACT is the limited tissue penetration of external light. Despite advances in the development of light source devices for phototherapy $[15,16]$ and the clinical use of PACT in dermatology $[5,17]$, treatment of internal body tissues remains limited to invasive procedures. Only a few attempts to develop alternative means of PS activation have been reported to date. We [18-20] and others [21] developed an approach in which the external light source was replaced by chemiluminescent light emitted during the course of a chemical reaction. We used the chemiluminescent oxidation of luminol, in which the release of light energy was achieved without electrical or thermal input in the course of in situ conversion of molecular oxygen to superoxide ions. This technology, called chemiluminescent photodynamic antimicrobial therapy (CPAT), was shown to be effective against Gram-negative E. coli and Gram-positive S. aureus (both methicillin-sensitive and methicillin-resistant strains) $[19,20]$. Our data showed that CPAT was almost as effective as PACT. CPAT can therefore compete with PACT 
in eradicating a wide range of Gram-positive and Gramnegative bacteria, including antibiotic-resistant strains. CPAT may thus become a novel antimicrobial therapeutic strategy and might be applicable for internal infections that are difficult to target and treat using traditional PACT.

Another interesting technique of PS activation that does not use an external light source is sonodynamic excitation by ultrasound. Sonodynamic therapy (SDT) based on ultrasound-induced cytotoxicity of compounds called sonosensitizers has already been studied for cancer cell inhibition. The sonosensitizers include widely used anti-cancer drugs such as bleomycin, adriamycin, amphotericin B, mitomycin C, daunomycin, diaziquone, and 5-fluorouracil [22], as well as several PS, such as hematoporphyrin, photofrin, mesoporphyrin, protoporphyrin, pheophorbide-a, ATX-70 (7,12-bis(1-decyloxyethyl)-Ga(III)-3,8,13,17-tetramethylporphyrin-2,18-dipropionyl diaspartic acid), Rose Bengal (RB), zinc(II)-phthalocyanine, and some others [22-29].

Generally speaking, the term SDT can be used for all nonthermally related therapeutic ultrasound applications, ranging from induction of apoptosis when combined with chemotherapy to ultrasound therapy. However, most authors use the term SDT for ultrasonic activation of drugs for cancer therapy [30]. The exact mechanism of SDT has not been entirely elucidated. Furthermore, it is assumed that there is no universal mechanism for synergism between ultrasound and drugs, such that different classes of sonosensitizers can be activated in the dark by different mechanisms [22, 31]. The biological effects of SDT are associated with one of three different mechanisms: heat, mechanical effects, and acoustic cavitation [32]. These effects depend on the intensity and frequency of the ultrasound: high intensity sonication leads to heat production, whereas low frequency treatment causes cavitation. Exposure of biological tissues to ultrasound can result in structural and/or functional changes of cells [32]. Mišík and Riesz believe that biological effects of SDT may be expressed due to one or two combinations of several factors: thermal effects (absorption and dissipation of ultrasound energy), cell membrane permeability changes and/or cell membrane rupture, and free radical effects [31]. The data obtained in their study show that photosensitizers (e.g., porphyrins) can be sonosensitized according to the following scheme: a drug undergoes pyrolysis inside collapsing cavitation bubbles or in the heated gas-liquid interface, forming free radical intermediates which react with dissolved oxygen to form peroxyl radicals, and the latter attack cellular sites due to their ability to diffuse to significant distances [31].

Other authors explain the sonodynamic effect of porphyrins by electronic excitation of the molecules by sonoluminescence, that is, light flashes produced during the course of acoustic cavitation in liquids generated with ultrasound energy without application of external illumination. Sonoluminescence initiates photochemical processes resulting in the formation of cytotoxic singlet oxygen [22, 29, 33].

A large number of serious studies are dedicated to SDT of cancer cells, and to the best of our knowledge, this technique has never been applied for eradication of bacteria. In 2009, Ma et al. [34] hypothesized that ultrasound

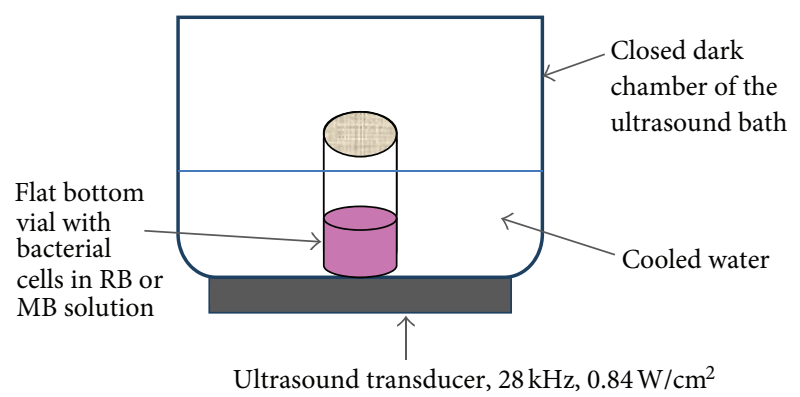

FIgure 1: The scheme for the SACT experiments. $2.5 \mathrm{~cm}$ diameter flat-bottomed vials with bacterial suspensions in $\mathrm{RB}$ or MB solutions were treated with $28 \mathrm{kHz}$ ultrasound at an intensity of $0.84 \mathrm{~W} \mathrm{~cm}^{-2}$ in an ultrasonic bath in the dark.

may be exploited for treatment of infectious bacterial and viral diseases and proposed a new concept of sonodynamic antimicrobial chemotherapy (SACT) as a promising novel antimicrobial strategy. However, this hypothesis has not been proven experimentally.

In the present work it is demonstrated, for the first time, that SACT can indeed be realized. We show that Grampositive S. aureus and Gram-negative E. coli can be eradicated by $\mathrm{RB}$ activated with ultrasound in the dark.

\section{Materials and Methods}

2.1. Bacterial Growth. Cultures of Staphylococcus aureus (ATCC 25923) and Escherichia coli (ATCC 10798) were grown on brain-heart agar (BHA, Acumedia, USA) for $24 \mathrm{~h}$, then were transferred into brain-heart broth $(\mathrm{BH}$, Acumedia, USA) and were grown at $37^{\circ} \mathrm{C}$ and at a $170 \mathrm{rpm}$ speed of shaking up to concentration of $10^{9} \mathrm{CFU} \mathrm{mL}^{-1}$, centrifuged for $5 \mathrm{~min}$ at 10,000 rpm and diluted by sterile $0.05 \mathrm{M} \mathrm{PBS}, \mathrm{pH}$ 7.5 , to concentrations of $106-109 \mathrm{CFU} \mathrm{mL}^{-1}$.

2.2. Solutions of PS. Stock aqueous solutions of RB and Methylene Blue (MB) (Sigma-Aldrich, USA) were prepared in $0.016 \mathrm{mM}$ and $0.013 \mathrm{mM}$ concentrations, respectively, in PBS and filtered by sterile filtration through $0.22 \mu \mathrm{m}$ membranes (Pall Corporation, USA). Visible spectra of the PS were registered using UV-Visible Spectrophotometer Cary 50 Bio (Varian, Australia).

2.3. Testing of SACT. PS solutions were added to $10 \mathrm{~mL}$ portions of diluted $S$. aureus or E. coli in flat-bottom $2.5 \mathrm{~cm}$ diameter vials (solution height in the vials was $2 \mathrm{~cm}$ ) and incubated for $15 \mathrm{~min}$ in the dark. Vials were held in a plastic holder tight to the bottom of an ultrasonic bath WUG$\mathrm{AO} 2 \mathrm{H}$ (Wise Clean Company, Korea) at $10^{\circ} \mathrm{C}$ and sonicated for $1-2 \mathrm{~h}$ at an ultrasound frequency of $28 \mathrm{kHz}$ and an intensity of $0.84 \mathrm{~W} \mathrm{~cm}^{-2}$ (Figure 1). Strict conditions were maintained in order to prevent any external illumination during the experiments. $100 \mu \mathrm{L}$ bacteria samples were diluted in several decimal dilutions and were spread over BHA plates with a Drigalsky spreader. The plates were incubated 
TABLE 1: SACT effect of RB on E. coli cells at various initial concentrations.

\begin{tabular}{|c|c|c|c|c|c|c|c|c|}
\hline \multirow{3}{*}{$\log _{10} C_{0}$} & \multicolumn{8}{|c|}{$\mathrm{RB}$ concentration, $\mu \mathrm{M}$} \\
\hline & \multicolumn{2}{|c|}{0} & \multicolumn{2}{|c|}{5} & \multicolumn{2}{|c|}{10} & \multicolumn{2}{|c|}{15} \\
\hline & $+^{*}$ & - & + & - & + & - & + & - \\
\hline 6 & 5.8 & 6.1 & 3.2 & 5.6 & 2.0 & 5.5 & 1.3 & 5.5 \\
\hline 7 & 7.0 & 6.9 & 5.6 & 6.8 & 4.5 & 6.3 & 3.7 & 6.3 \\
\hline 9 & 7.1 & 9.0 & 6.8 & 9.0 & 6.0 & 8.2 & 5.0 & 8.1 \\
\hline
\end{tabular}

${ }^{*}$ Plus (+) designates SACT treated samples and minus (-) designates controls. Treatment time was $1 \mathrm{~h} . \mathrm{C}_{0}$ : initial cell concentration, $\mathrm{CFU} \mathrm{mL}^{-1}$.

at $37^{\circ} \mathrm{C}$ overnight and $\mathrm{CFU}$ (colony-forming units) were counted taking dilutions into account. In control experiments bacterial cultures were tested in the absence of PS without sonication, in the absence of PS under sonication and in the presence of PS without sonication.

2.4. Testing of PACT. PACT experiments were carried out by illumination of bacteria cultured as described above in liquid $\mathrm{BH}$ medium, mixed with solutions of $\mathrm{MB}$ in glass test-tubes, incubated for $15 \mathrm{~min}$ in the dark and illuminated for $30 \mathrm{~min}$ at room temperature under temperature control by an $18 \mathrm{~W}$ white luminescent lamp placed at a distance of $15 \mathrm{~cm}$ from the tubes. Light intensity was $10.6 \mathrm{klux}$ and a fluence rate was $1.6 \mathrm{~mW} \mathrm{~cm}^{-2}$. Light intensity was measured by a LX-102 Light-meter (Lutron, Taiwan). Samples were not sonicated in the PACT experiments.

2.5. Statistical Methods. The results obtained from at least 3 independent experiments fulfilled with duplicates were statistically analyzed by Anova single factor or by Anova two-factor analyses. The difference between the results was considered significant if the $P$ value was less than 0.05 .

\section{Results and Discussion}

Two types of cells were chosen for primary evaluation of the suitability of SDT for eradication of bacteria-E. coli for representing Gram-negative bacteria and S. aureus as a member of the Gram-positive group. Two compounds, RB and $\mathrm{MB}$, were selected as potential sonosensitizers. These compounds are well known for their photodynamic activity against the chosen bacteria [19, 35-39], and what is more, sonodynamic anticancer activity of $\mathrm{RB}$ has been reported in several works $[26,40]$. The sonodynamic activity of $\mathrm{MB}$ has not been studied, to the best of our knowledge, but several authors believe that photosensitizers are generally good candidates for exhibiting sonodynamic properties [22, 28]. $R B$ and $M B$ have good solubility in water, and this fact enabled building an experimental scheme based on their free forms in aqueous solutions.

The experiments for testing sonodynamic antibacterial properties of $\mathrm{RB}$ and $\mathrm{MB}$ were held in the dark in an ultrasonic bath with cold water (Figure 1). Pieces of ice were periodically added to the bath in order to compensate for heating of the water during the sonication procedure. All operations were performed in the dark in order to exclude any possibility of photodynamic excitation of the examined

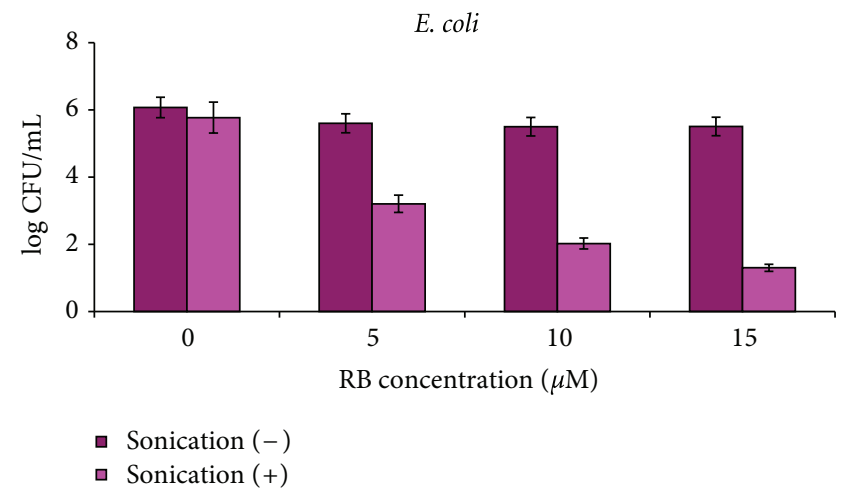

FIgURE 2: SACT effect of RB on E. coli. Cells at initial concentration of $10^{6} \mathrm{CFU} \mathrm{mL} \mathrm{mL}^{-1}$ were incubated with $0-15 \mu \mathrm{M} \mathrm{RB}$ in an ultrasonic bath for $1 \mathrm{~h}$ in the dark. Controls: not sonicated bacterial cultures with or without PS. After the treatment, bacterial samples were serially diluted in 10-fold dilutions and evenly spread over BHA plates with a Drigalsky spreader. Plates were incubated at $37^{\circ} \mathrm{C}$ overnight and CFU were counted.

compounds. The following control experiments were carried out in all series in the dark: incubation of bacteria without sonication in the absence of $\mathrm{RB}$ and $\mathrm{MB}$, incubation of bacteria without sonication in the presence of $\mathrm{RB}$ or $\mathrm{MB}$, and sonication of bacteria in the absence of $\mathrm{RB}$ and $\mathrm{MB}$. Various concentrations of the bacterial cultures were added to buffered aqueous solutions of RB or MB in flat vials and placed on the bottom of the ultrasound bath for sonication (Figure 1). The control vials, which were not sonicated, were incubated under similar conditions outside the bath in the dark.

The results of the SACT experiments demonstrating a sonodynamic effect of RB on E. coli are presented in Table 1 and Figure 2, and on S. aureus in Table 2 and Figure 3. When treated for $1 \mathrm{~h}$, both $E$. coli and $S$. aureus bacteria were inhibited by RB under each tested concentration, and an increase in RB concentration caused higher suppression. Sonication of the cultures in the absence of $\mathrm{RB}$ led to a moderate decrease in cell concentration: sonication of cultures at a high initial bacterial concentration of $E$. coli $\left(10^{9} \mathrm{CFU} \mathrm{mL} \mathrm{m}^{-1}\right)$ resulted in a ca. $2 \log _{10}$ decrease in the number of CFU (Table 1), whereas sonication at a low initial concentration $\left(10^{6}\right.$ and $\left.10^{7} \mathrm{CFU} \mathrm{mL}^{-1}\right)$ had no effect on the vitality of the bacteria when compared to the untreated control cells $(P$ value $=0.322)$. Sonication of $S$. aureus not treated by $\mathrm{RB}$ resulted in a $c a .1 \log _{10}$ decrease in the bacterial concentration for all initial bacterial cell concentrations 
TABLE 2: SACT effect of RB on S. aureus cells at various initial concentrations.

\begin{tabular}{|c|c|c|c|c|c|c|c|c|}
\hline \multirow{3}{*}{$\log _{10} C_{0}$} & \multicolumn{8}{|c|}{ RB concentration, $\mu \mathrm{M}$} \\
\hline & \multicolumn{2}{|c|}{0} & \multicolumn{2}{|c|}{1.5} & \multicolumn{2}{|c|}{3} & \multicolumn{2}{|c|}{5} \\
\hline & $+^{*}$ & - & + & - & + & - & + & - \\
\hline 6 & 5.0 & 5.7 & 1.4 & 5.3 & 0.8 & 4.2 & 0.01 & 3.6 \\
\hline 7 & 6.0 & 6.9 & 3.7 & 5.8 & 2.9 & 5.6 & 1.7 & 5.6 \\
\hline 9 & 7.9 & 8.9 & 6.6 & 8.5 & 6.3 & 7.8 & 5.4 & 7.5 \\
\hline
\end{tabular}

" Plus (+) designates SACT treated samples and minus (-) designates controls. Treatment time was $1 \mathrm{~h} . \mathrm{C}_{o}$ : initial cell concentration, $\mathrm{CFU} \mathrm{mL}^{-1}$.

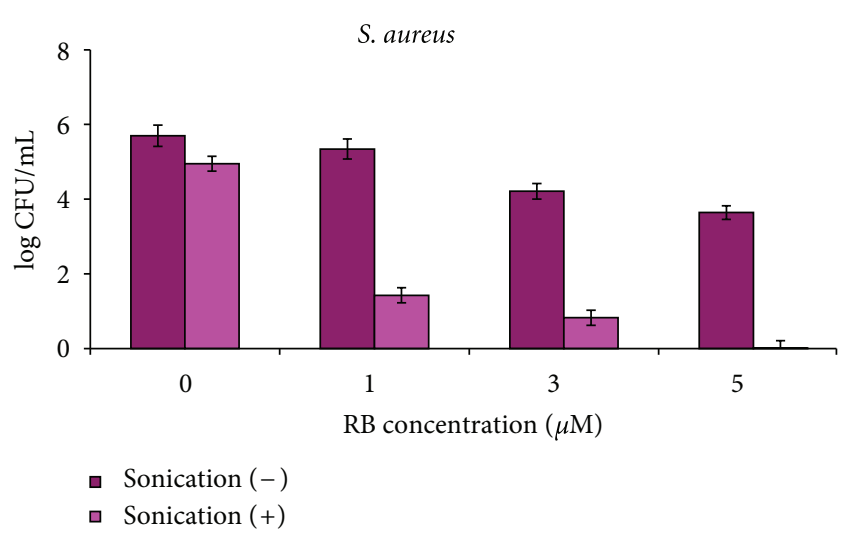

FIGURE 3: SACT effect of RB on S. aureus. Cells at initial concentration of $10^{6} \mathrm{CFU} \mathrm{mL}^{-1}$ were incubated with $0-5 \mu \mathrm{M} \mathrm{RB}$ in an ultrasonic bath for $1 \mathrm{~h}$ in the dark. Controls: not sonicated bacterial cultures with or without PS. After the treatment, bacterial samples were serially diluted in 10-fold dilutions and evenly spread over BHA plates with a Drigalsky spreader. Plates were incubated at $37^{\circ} \mathrm{C}$ overnight and CFU were counted.

(Table 2). Incubation of both bacteria in the absence of RB without sonication did not change the concentration of viable cells in all cases (Tables 1 and 2). The dark effect of RB, registered in nonsonicated series, depended on the initial cell concentration: for $E$. coli the maximal dark effect was ca. a $1 \log _{10}$ decrease $(P$ value $=0.023)$ in CFU obtained for $15 \mu \mathrm{M}$ RB at initial concentration of $10^{9} \mathrm{CFU} \mathrm{mL}^{-1}$ (Table 1). This effect was even smaller and actually, insignificant, in the case of initial concentrations of $10^{6}$ and $10^{7} \mathrm{CFU} \mathrm{mL}^{-1}$ for all RB concentrations - a $0.1-0.6 \log _{10}$ decrease in the E. coli vitality compared to the untreated control cells $(P$ values $=$ 0.40-0.72). For $S$. aureus the maximal dark effect was higher than that for E. coli-at $5 \mu \mathrm{M} \mathrm{RB}$ for all initial concentrations the vitality of $S$. aureus cells decreased by $1.5-2.5 \log _{10}$ in comparison with untreated cells $(P$ values $=0.0238)($ Table 2$)$. Actually, in no case did application of either ultrasound or RB separately result in high suppression of the tested bacteria. Simultaneous use of RB and ultrasound in the dark showed quite different results. Inhibition of the treated by $15 \mu \mathrm{M}$ RB E. coli cells was expressed by a $4-4.7 \log _{10}$ decrease in CFU compared to the untreated samples $(P$ value $=0.041)$, (Table 1), and the highest eradication rate was achieved for an initial bacterial concentration of $10^{6} \mathrm{CFU} \mathrm{mL}^{-1}$ treated by $15 \mu \mathrm{MRB}$, where the remaining $E$. coli concentration dropped to only $20 \mathrm{CFU} \mathrm{mL} \mathrm{mL}^{-1}$ (Figure 2). S. aureus was even more sensitive to the sonodynamic treatment. The bacteria were suppressed by $3.5-6 \log _{10}$ compared to the untreated samples $(P$ values $=0.0078-0.018)$ at all initial cell concentrations (Table 2), and treatment by $5 \mu \mathrm{M} \mathrm{RB}$ at an initial concentration of $10^{6} \mathrm{CFU} \mathrm{mL} \mathrm{m}^{-1}$ led to the most profound eradication of $S$. aureus (Figure 3 ). Taking into consideration separate dark and ultrasonic effects, we can conclude that the net contribution of sonodynamic treatment in the dark was ca. a $3 \log _{10}$ decrease in CFU. In the cases of both bacteria, application of SACT led to the antibacterial cytotoxic effect.

Prolonging the sonication caused a total bacterial suppression even at higher initial cell concentrations. S. aureus at an initial concentration of $10^{7} \mathrm{CFU} \mathrm{mL}^{-1}$ and sonicated for $2 \mathrm{~h}$ in the presence of $5 \mu \mathrm{M} \mathrm{RB}$ was deeply eradicated, whereas after a $1 \mathrm{~h}$ treatment the number of viable cells was $50 \mathrm{CFU} \mathrm{mL}^{-1}$ (Figure 4).

Another PS previously shown to be very effective in photodynamic eradication of the bacteria examined in the present study $[19,20,38,39]$, namely $\mathrm{MB}$, was tested under SACT conditions. $S$. aureus was studied at two initial concentrations of $10^{9}$ and $10^{6} \mathrm{CFU} \mathrm{mL} \mathrm{m}^{-1}$. MB demonstrated a low dark effect in the absence of sonication and the concentration of $S$. aureus cells decreased by $1.2 \log _{10}$ at both initial cell concentrations. At initial bacterial concentration of $10^{9} \mathrm{CFU} \mathrm{mL} \mathrm{m}^{-1}$ sonication in the absence of $\mathrm{MB}$ caused a $1.4 \log _{10}$ decrease in CFU, and in the presence of $\mathrm{MB}-\mathrm{a}$ $1.7 \log _{10}$ reduction in the $S$. aureus concentration. The difference between these data was insignificant $(P$ value $=0.39)$. In the case of initial cell concentration of $10^{6} \mathrm{CFU} \mathrm{mL}^{-1}$ the difference was even less (Figure 5) and reached a $0.26 \log _{10}$ decrease in the absence of $\mathrm{MB}$ and a $0.3 \log _{10}$ decrease in the presence of $\mathrm{MB}(P$ value $=0.76)$ The results of the control experiments were very similar to those obtained in the $\mathrm{RB}$ study (Table 2), but in contradistinction to $\mathrm{RB}, \mathrm{MB}$ was not found to exhibit any sonodynamic activity. Additional control experiments on the photodynamic activity of $\mathrm{MB}$ were performed in order to rule out possible occasional inactivity of the batch of $\mathrm{MB}$ used for $S$. aureus eradication. $S$. aureus illuminated by white light in the absence of $\mathrm{MB}$ was practically unaffected, whereas the bacteria were totally eradicated in the presence of MB (Figure 5).

Inefficiency of $\mathrm{MB}$ in the SACT experiment was quite surprising for us and it can be assumed that not all the PS can be excited by ultrasound. Probably, sensitivity of PS to sonication depends on the structure of the molecules, especially 


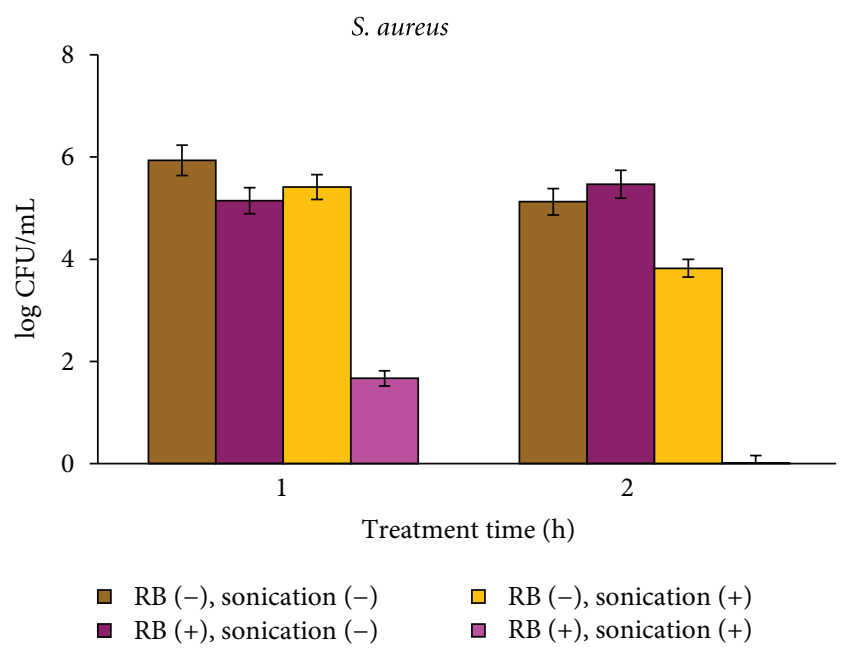

FIGURE 4: Effect of treatment time on SACT activity of RB. S. aureus cells at an initial concentration of $10^{7} \mathrm{CFU} \mathrm{mL}^{-1}$ were incubated with $5 \mu \mathrm{M}$ RB in an ultrasonic bath for 1 and $2 \mathrm{~h}$ in the dark. After the treatment, bacteria were tested by viable count.

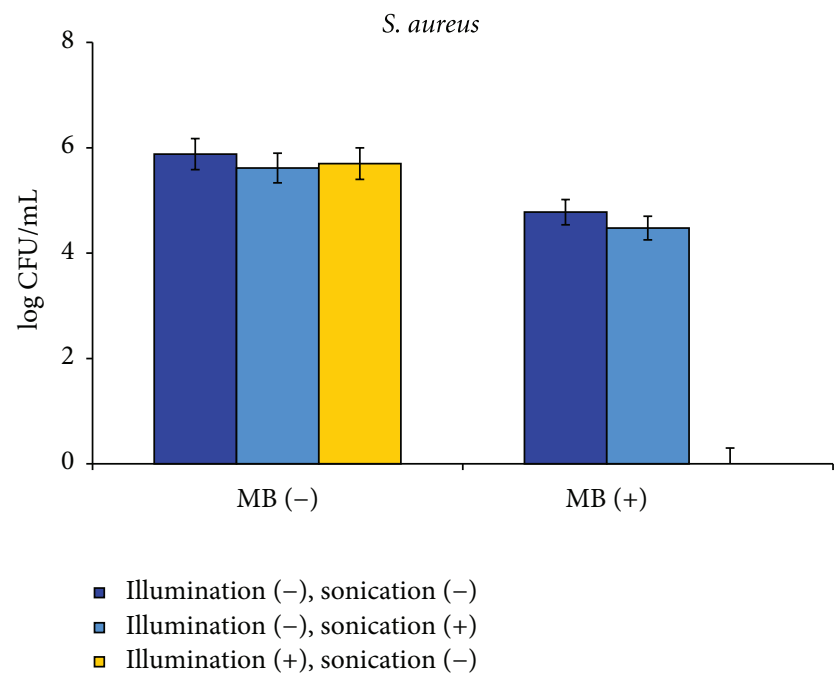

Figure 5: SACT and PACT effect of MB on S. aureus. Cells at $10^{6} \mathrm{CFU} \mathrm{mL} \mathrm{mL}^{-1}$ concentration were incubated with $30 \mu \mathrm{M} \mathrm{MB}$ in ultrasonic bath for $1 \mathrm{~h}$ in the dark. In PACT experiments, the cells were illuminated for $0.5 \mathrm{~h}$ with $1.6 \mathrm{~mW} \mathrm{~cm}^{-2}$ white light under the same conditions but without sonication. After the treatment, bacteria were tested by viable count.

on their hydrophoby and electrical charge. Undoubtedly, for more profound investigation of this issue additional studies should be carried out, including variation in PS, in their concentrations and application of ultrasound in a wide range of intensities.

We have previously examined the effect of free $\mathrm{RB}$ on S. aureus under photodynamic activation $[38,39]$ and can now compare PACT with SACT by this compound for the same initial bacterial concentration of $10^{7} \mathrm{CFU} \mathrm{mL}^{-1}$. As was shown in [39] total eradication of cells under PACT conditions took place at $1 \mu \mathrm{M} \mathrm{RB}$ excited by white light

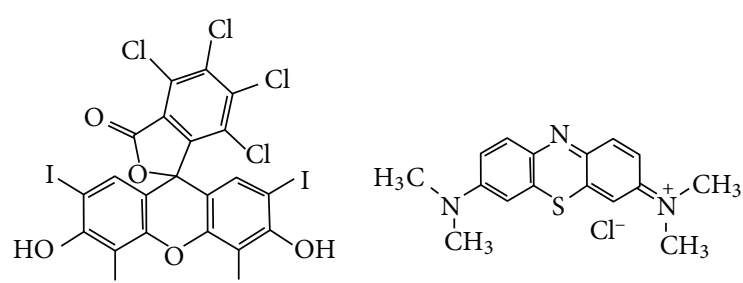

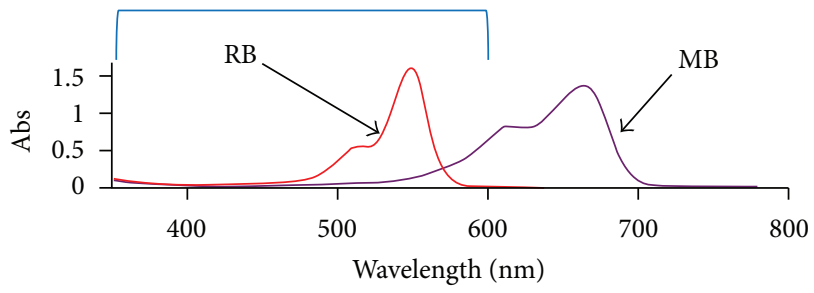

FIGURE 6: Visible absorption spectra of $0.016 \mathrm{mMRB}$ and $0.013 \mathrm{mMMB}$ aqueous solutions. Structures of $\mathrm{RB}$ and $\mathrm{MB}$ are shown above the spectra.The region of maximal emission intensity of sonoluminescence in wateris designated by a blue bracket.

at a fluence rate of $1.6 \mathrm{~mW} \mathrm{~cm}{ }^{-2}$ applied for half an hour, whereas the same result under the SACT regime in dark conditions was achieved at $5 \mu \mathrm{M} \mathrm{RB}$ activated by ultrasound applied for two hours at an intensity of $0.84 \mathrm{~W} \mathrm{~cm}^{-2}$ and a frequency of $28 \mathrm{kHz}$. The difference between PACT and SACT was even more drastic for MB. As demonstrated in the present work, S. aureus was totally eradicated when activated by light at the same $\mathrm{MB}$ and cell concentrations and was almost unaffected when excited by ultrasound (Figure 5). These data demonstrate that overall, PACT is a more effective tool than SACT, but the efficiency of the latter can probably be increased by application of ultrasound at higher intensities or at different frequencies, thus transforming this technique into a practical and convenient tool for bacterial suppression under dark conditions. This issue needs to be investigated further.

The obtained data provide indirect evidence that the mechanism of SACT is probably based on sonoluminescent excitation of PS. Sonoluminescent light has a broadband spectrum from 200 to $700 \mathrm{~nm}$, but the maximum emission intensity of sonoluminescence in water lies between 250 and $600 \mathrm{~nm}$ [41]. This emission range correlates well with the absorbance spectrum of RB, but has almost no overlap with the spectrum of $\mathrm{MB}$ (Figure 6), thus affording an explanation for the high rate of RB activation by SACT and negligible sonoexcitation of $\mathrm{MB}$.

Figures 2 and 3 demonstrate that the Gram-positive $S$. aureus responded to the sonodynamic treatment with $\mathrm{RB}$ much better than the Gram-negative E. coli, where the eradication rates were higher at lower applied RB concentrations for all initial cell concentrations. The same tendency was observed for PACT $[38,39]$ and was explained by differences in the complex molecular and physico-chemical structure of the cell membranes of the two bacterial groups [42]. The initial cell concentration played a crucial role in the process of bacterial eradication by SACT. For all examined 
concentrations of RB the SACT effect was more pronounced for low initial bacterial concentrations and less exhibited for concentrated bacterial suspensions. The highest eradication of both bacteria was achieved when cells at low concentration were treated by PS at high concentration (Tables 1 and 2). Probably SACT effect depends on PS dose to bacterial concentration ratio. Analogous phenomenon of different effect of PS on bacterial cells at various concentrations was registered earlier in PACT experiments [39] and it was shown that at low concentrations bacteria showed stronger susceptibility for PACT treatment.

As in the case of cancer treatment, combating bacterial infections in vivo can be more effective and with fewer side effects when targeted to the site of infection. In addition to known methods of targeting drugs to cells, including antibody, protein or peptide, liposomal, and magnetic targeting [43-50], use of ultrasound affords a direct and exact focusing on the treated site. Nonactivated PS does not harm healthy tissues. Thus, excitation of the PS only after it has reached the treatment site will prevent systemic toxic effects during delivery of the drug to the treatment site. Such targeted treatment was carried out on cancer cells in mice by Yumita et al. [29] and Umemura et al. [51] and resulted in cessation of tumor growth [51] or even in destruction of tumor tissue [29]. The same targeting scheme can undoubtedly be applied for antibacterial treatment.

In addition to future potential therapeutic applications of SACT, a method for cold sterilization of medical instruments and surgical accessories could be proposed. A simple addition of sonosensitizers, for example of $\mathrm{RB}$, to the aqueous phase in the ultrasonic bath will significantly improve and increase the effectiveness of the sterilization process.

\section{Conclusions}

The present work shows for the first time, that sonodynamic activation of RB causes eradication of E. coli and S. aureus in the dark. The described novel SACT technique has good prospects for becoming an effective targeted tool for combating internal infections and for cold sterilization of medical instruments.

\section{Acknowledgments}

This research was supported in part by the Research Authority of the Ariel University Center of Samaria, Israel, by the Cherna Moskowitz Foundation, Calif, USA, and by the Rappaport Foundation for Medical Microbiology, Bar Ilan University, Israel (to Y. Nitzan).

\section{References}

[1] T. Maisch, "Anti-microbial photodynamic therapy: useful in the future?” Lasers in Medical Science, vol. 22, no. 2, pp. 83-91, 2007.

[2] T. Maisch, "A new strategy to destroy antibiotic resistant microorganisms: antimicrobial photodynamic treatment," MiniReviews in Medicinal Chemistry, vol. 9, no. 8, pp. 974-983, 2009.
[3] I. E. Kochevar, C. R. Lambert, M. C. Lynch, and A. C. Tedesco, "Comparison of photosensitized plasma membrane damage caused by singlet oxygen and free radicals," Biochimica et Biophysica Acta, vol. 1280, no. 2, pp. 223-230, 1996.

[4] I. J. MacDonald and T. J. Dougherty, "Basic principles of photodynamic therapy," Journal of Porphyrins and Phthalocyanines, vol. 5, no. 2, pp. 105-129, 2001.

[5] T. Maisch, R. M. Szeimies, G. Jori, and C. Abels, "Antibacterial photodynamic therapy in dermatology," Photochemical and Photobiological Sciences, vol. 3, no. 10, pp. 907-917, 2004.

[6] S. Yano, S. Hirohara, M. Obata et al., "Current states and future views in photodynamic therapy," Journal of Photochemistry and Photobiology C, vol. 12, no. 1, pp. 46-67, 2011.

[7] K. Plaetzer, T. Kiesslich, T. Verwanger, and B. Krammer, "The modes of cell death induced by PDT: an overview," Medical Laser Application, vol. 18, no. 1, pp. 7-19, 2003.

[8] J. Berlanda, T. Kiesslich, V. Engelhardt, B. Krammer, and K. Plaetzer, "Comparative in vitro study on the characteristics of different photosensitizers employed in PDT," Journal of Photochemistry and Photobiology B, vol. 100, no. 3, pp. 173-180, 2010.

[9] M. Wainwright, "Photodynamic antimicrobial chemotherapy (PACT)," Journal of Antimicrobial Chemotherapy, vol. 42, no. 1, pp. 13-28, 1998.

[10] C. M. Cassidy, M. M. Tunney, P. A. McCarron, and R. F. Donnelly, "Drug delivery strategies for photodynamic antimicrobial chemotherapy: from benchtop to clinical practice," Journal of Photochemistry and Photobiology B, vol. 95, no. 2, pp. 71-80, 2009.

[11] K. O'Riordan, O. E. Akilov, and T. Hasan, “The potential for photodynamic therapy in the treatment of localized infections," Photodiagnosis and Photodynamic Therapy, vol. 2, no. 4, pp. 247-262, 2005.

[12] P. Meisel and T. Kocher, "Photodynamic therapy for periodontal diseases: state of the art," Journal of Photochemistry and Photobiology B, vol. 79, no. 2, pp. 159-170, 2005.

[13] T. Dai, Y. Y. Huang, and M. R. Hamblin, "Photodynamic therapy for localized infections-state of the art," Photodiagnosis and Photodynamic Therapy, vol. 6, no. 3-4, pp. 170-188, 2009.

[14] A. Tavares, C. M. B. Carvalho, M. A. Faustino et al., "Antimicrobial photodynamic therapy: study of bacterial recovery viability and potential development of resistance after treatment," Marine Drugs, vol. 8, no. 1, pp. 91-105, 2010.

[15] L. Brancaleon and H. Moseley, "Laser and non-laser light sources for photodynamic therapy," Lasers in Medical Science, vol. 17, no. 3, pp. 173-186, 2002.

[16] A. Pieslinger, K. Plaetzer, C. B. Oberdanner et al., "Characterization of a simple and homogeneous irradiation device based on light-emitting diodes: a possible low-cost supplement to conventional light sources for photodynamic treatment," Medical Laser Application, vol. 21, no. 4, pp. 277-283, 2006.

[17] O. Ceburkov and H. Gollnick, "Photodynamic therapy in dermatology," European Journal of Dermatology, vol. 10, no. 7, pp. 568-576, 2000.

[18] R. Laptev, M. Nisnevitch, G. Siboni, Z. Malik, and M. A. Firer, "Intracellular chemiluminescence activates targeted photodynamic destruction of leukaemic cells," British Journal of Cancer, vol. 95, no. 2, pp. 189-196, 2006.

[19] F. Nakonechny, M. A. Firer, Y. Nitzan, and M. Nisnevitch, "Intracellular antimicrobial photodynamic therapy: a novel technique for efficient eradication of pathogenic bacteria," 
Photochemistry and Photobiology, vol. 86, no. 6, pp. 1350-1355, 2010.

[20] F. Nakonechny, M. Nisnevitch, Y. Nitzan, and M. A. Firer, "New techniques in antimicrobial photodynamic therapy: scope of application and overcoming drug resistance in nosocomial infections," in Science Against Microbial Pathogens: Communicating Current Research and Technological Advances, Microbiology Book Series, no. 3, Formatex Research Center, Spain, 2011.

[21] S. Carpenter, M. J. Fehr, G. A. Kraus, and J. W. Petrich, "Chemiluminescent activation of the antiviral activity of hypericin: a molecular flashlight," Proceedings of the National Academy of Sciences of the United States of America, vol. 91, no. 25, pp. 12273-12277, 1994.

[22] I. Rosenthal, J. Z. Sostaric, and P. Riesz, "Sonodynamic therapy-a review of the synergistic effects of drugs and ultrasound," Ultrasonics Sonochemistry, vol. 11, no. 6, pp. 349-363, 2004.

[23] P. Wang, L. Xiao, X. Wang, X. Li, and Q. Liu, "Sonodynamic effects of protoporphyrin IX disodium salt on Ehrlich ascetic tumor cells," Ultrasonics, vol. 50, no. 6, pp. 634-638, 2010.

[24] X. Zhao, Q. Liu, W. Tang et al., "Damage effects of protoporphyrin IX-sonodynamic therapy on the cytoskeletal F-actin of Ehrlich ascites carcinoma cells," Ultrasonics Sonochemistry, vol. 16, no. 1, pp. 50-56, 2009.

[25] Y. He, D. Xing, G. Yan, and K. I. Ueda, "FCLA chemiluminescence from sonodynamic action in vitro and in vivo," Cancer Letters, vol. 182, no. 2, pp. 141-145, 2002.

[26] S. I. Umemura, N. Yumita, K. Umemura, and R. Nishigaki, "Sonodynamically induced effect of rose bengal on isolated sarcoma 180 cells," Cancer Chemotherapy and Pharmacology, vol. 43 , no. 5, pp. 389-393, 1999.

[27] A. Juarranz, J. Espada, J. C. Stockert et al., "Photodamage induced by Zinc(II)-phthalocyanine to microtubules, actin, alpha-actinin and keratin of HeLa cells.," Photochemistry and Photobiology, vol. 73, no. 3, pp. 283-289, 2001.

[28] L. L. He, X. Wang, B. Liu, J. Wang, Y. G. Sun, and S. $\mathrm{K} . \mathrm{Xu}$, "Study on the sonodynamic activity and mechanism of promethazine hydrochloride by multi-spectroscopic techniques," Spectrochimica Acta. Part A, vol. 81, pp. 698-705, 2011.

[29] N. Yumita, K. Sasaki, S. I. Umemura, A. Yukawa, and R. Nishigaki, "Sonodynamically induced antitumor effect of galliumporphyrin complex by focused ultrasound on experimental kidney tumor," Cancer Letters, vol. 112, no. 1, pp. 79-86, 1997.

[30] K. Tachibana, L. B. Feril, and Y. Ikeda-Dantsuji, "Sonodynamic therapy," Ultrasonics, vol. 48, no. 4, pp. 253-259, 2008.

[31] V. Mišík and P. Riesz, "Free radical intermediates in sonodynamic therapy," Annals of the New York Academy of Sciences, vol. 899, pp. 335-348, 2000.

[32] T. Yu, Z. Wang, and T. J. Mason, "A review of research into the uses of low level ultrasound in cancer therapy," Ultrasonics Sonochemistry, vol. 11, no. 2, pp. 95-103, 2004.

[33] N. Yumita, R. Nishigaki, K. Umemura, and S. Umemura, "Synergistic effect of ultrasound and hematoporphyrin on sarcoma 180," Japanese Journal of Cancer Research, vol. 81, no. 3, pp. 304-308, 1990.

[34] X. Ma, H. Pan, G. Wu, Z. Yang, and J. Yi, "Ultrasound may be exploited for the treatment of microbial diseases," Medical Hypotheses, vol. 73, no. 1, pp. 18-19, 2009.

[35] T. N. Demidova and M. R. Hamblin, "Photodynamic inactivation of Bacillus spores, mediated by phenothiazinium dyes," Applied and Environmental Microbiology, vol. 71, no. 11, pp. 6918-6925, 2005.
[36] M. Schafer, C. Schmitz, R. Facius et al., "Systematic study of parameters influencing the action of Rose Bengal with visible light on bacterial cells: comparison between the biological effect and singlet-oxygen production," Photochemistry and Photobiology, vol. 71, pp. 514-523, 2000.

[37] M. N. Usacheva, M. C. Teichert, and M. A. Biel, "Comparison of the methylene blue and toluidine blue photobactericidal efficacy against gram-positive and gram-negative microorganisms," Lasers in Surgery and Medicine, vol. 29, no. 2, pp. 165-173, 2001.

[38] M. Nisnevitch, F. Nakonechny, and Y. Nitzan, "Photodynamic antimicrobial chemotherapy by liposome-encapsulated watersoluble photosensitizers," Russian Journal of Bioorganic Chemistry, vol. 36, no. 3, pp. 363-369, 2010.

[39] F. Nakonechny, Y. Nitzan, and M. Nisnevitch, "Olive oil based delivery of photosensitizes for bacterial eradication," in Olive Oil, InTech, Rijeka, Croatia, 2012.

[40] W. Hiraoka, H. Honda, L. B. Feril, N. Kudo, and T. Kondo, "Comparison between sonodynamic effect and photodynamic effect with photosensitizers on free radical formation and cell killing," Ultrasonics Sonochemistry, vol. 13, no. 6, pp. 535-542, 2006.

[41] S. I. Hatanaka, H. Mitome, K. Yasui, and S. Hayashi, "Singlebubble sonochemiluminescence in aqueous luminol solutions," Journal of the American Chemical Society, vol. 124, no. 35, pp. 10250-10251, 2002.

[42] P. D. Sharma, "Microbiology," Rastogy Publications, New Delphy, India, 2007.

[43] M. N. Jones, M. Kaszuba, K. J. Hill, Y. H. Song, and J. E. Creeth, "The use of phospholipid liposomes for targeting to oral and skin-associated bacteria," Journal of Drug Targeting, vol. 2, no. 5, pp. 381-389, 1994.

[44] M. N. Jones, M. Kaszuba, M. D. Reboiras et al., “The targeting of phospholipid liposomes to bacteria," Biochimica et Biophysica Acta, vol. 1196, no. 1, pp. 57-64, 1994.

[45] A. M. Robinson, J. E. Creeth, and M. N. Jones, “The specificity and affinity of immunoliposome targeting to oral bacteria," Biochimica et Biophysica Acta, vol. 1369, no. 2, pp. 278-286, 1998.

[46] P. Fekkes and A. J. M. Driessen, "Protein targeting to the bacterial cytoplasmic membrane," Microbiology and Molecular Biology Reviews, vol. 63, no. 1, pp. 161-173, 1999.

[47] A. S. Manjappa, K. R. Chaudhari, M. P. Venkataraju et al., "Antibody derivatization and conjugation strategies: application in preparation of stealth immunoliposome to target chemotherapeutics to tumor," Journal of Controlled Release, vol. 150, no. 1, pp. 2-22, 2011.

[48] J. H. Ryu, H. Koo, I. C. Sun et al., “Tumor-targeting multifunctional nanoparticles for theragnosis: new paradigm for cancer therapy," Advanced Drug Delivery Reviews. In press.

[49] H. A. Franks, Q. Wang, and P. M. Patel, "New anticancer immunotherapies," Anticancer Research, vol. 32, no. 7, pp. 2439-2453, 2012.

[50] S. Cohen, R. Cahan, E. Ben-Dov, M. Nisnevitch, A. Zaritsky, and M. A. Firer, "Specific targeting to murine myeloma cells of Cyt1Aa toxin from Bacillus thuringiensis subspecies israelensis," Journal of Biological Chemistry, vol. 282, no. 39, pp. 28301-28308, 2007.

[51] K. Umemura, N. Yumita, R. Nishigaki, and S. I. Umemura, "Sonodynamically induced antitumor effect of pheophorbide a," Cancer Letters, vol. 102, no. 1-2, pp. 151-157, 1996. 

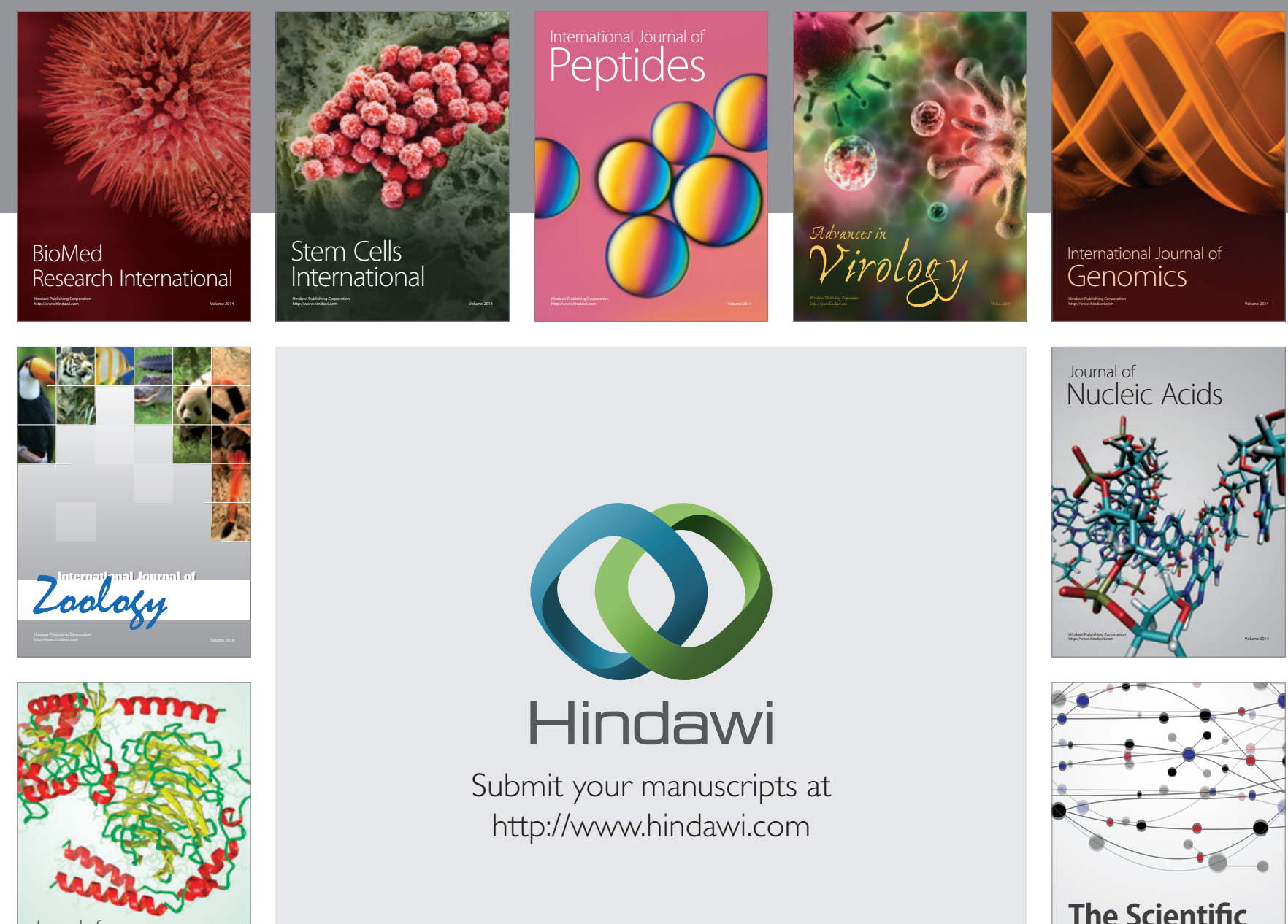

Submit your manuscripts at

http://www.hindawi.com

Journal of
Signal Transduction
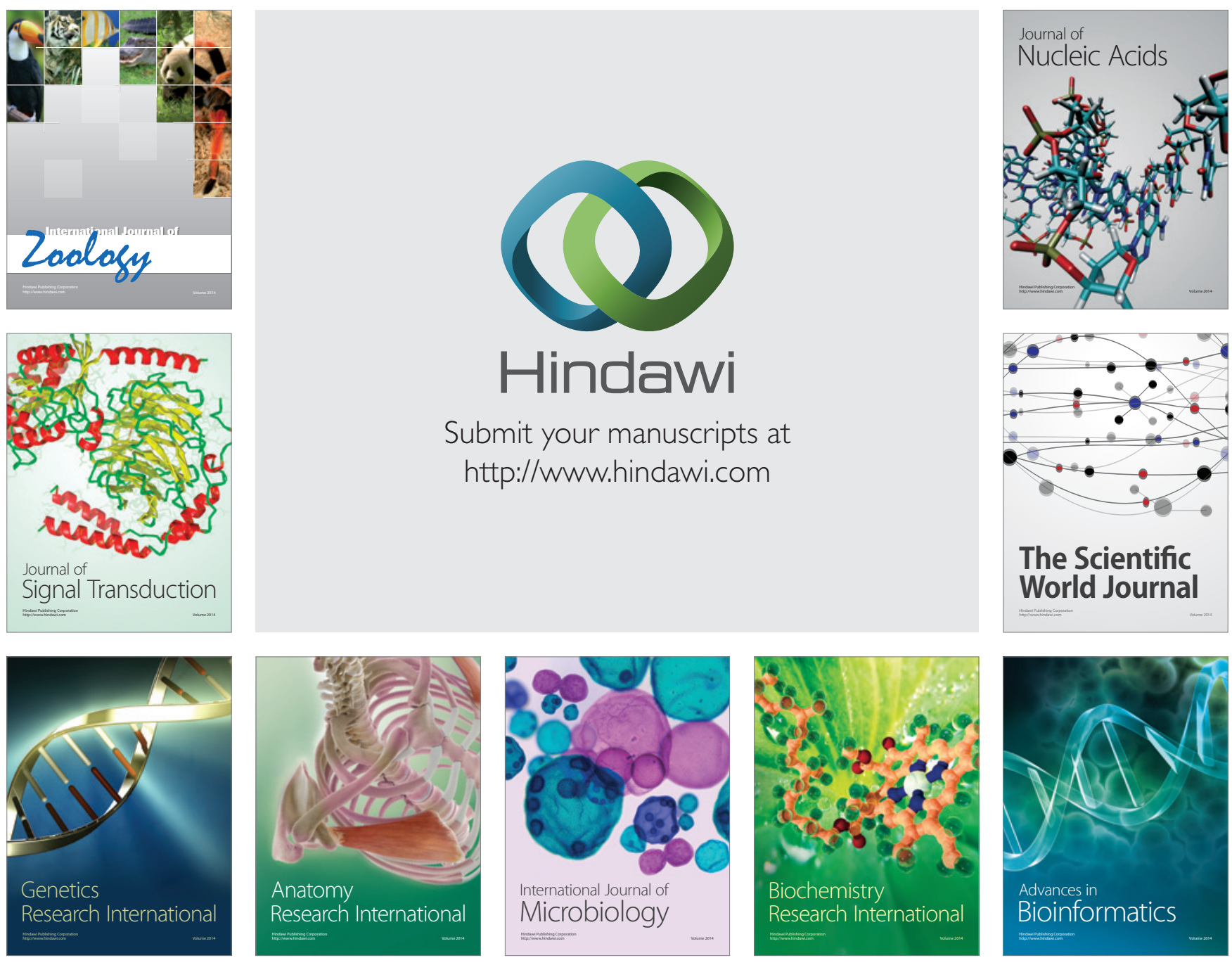

The Scientific World Journal
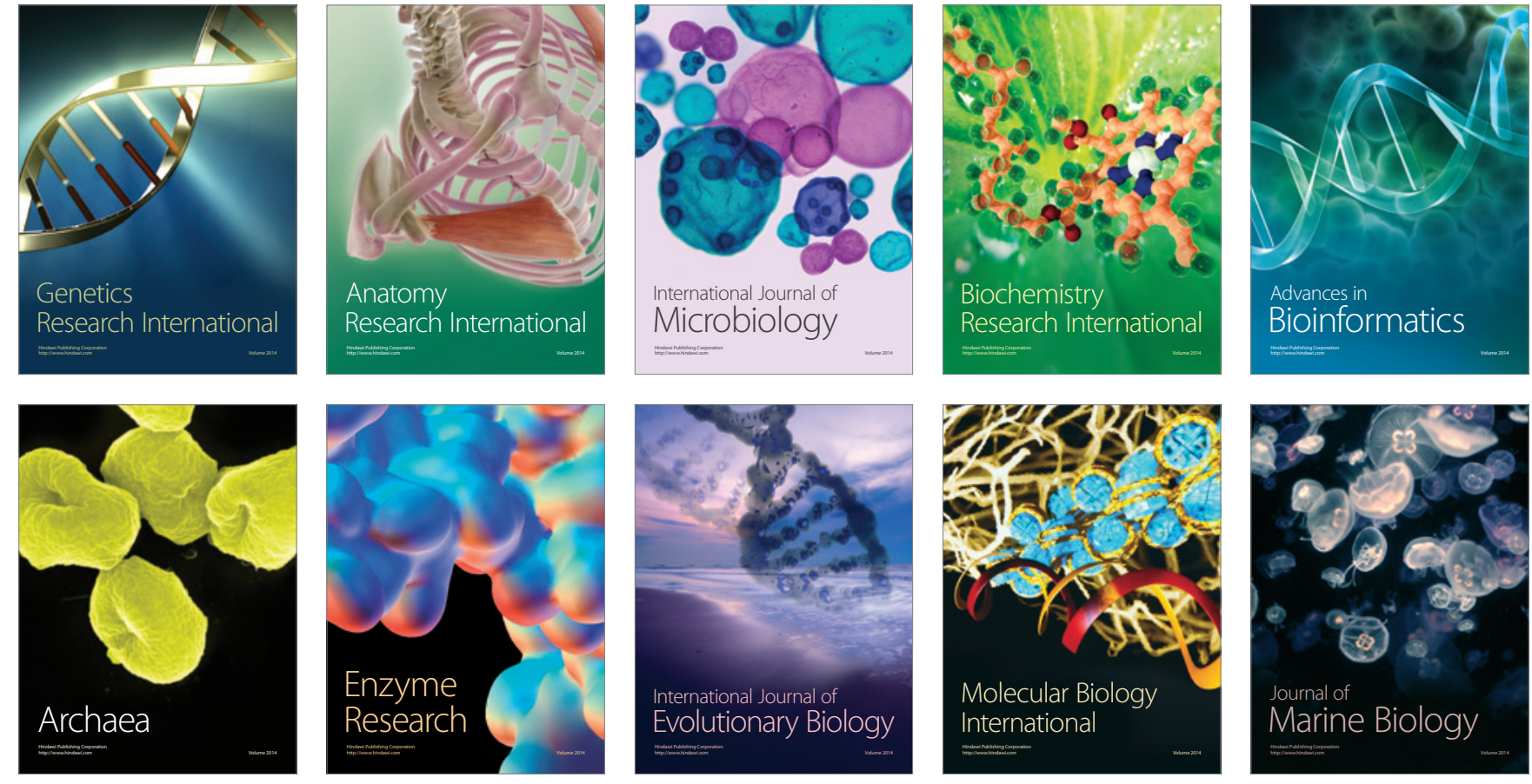